\title{
Enriching Mannix Library's Rare Materials
}

by Huw Sandaver

At the beginning of 2016, the special collection of Mannix Library-part of the Catholic Theological College in East Melbourne, Australia-extended to just under two thousand sparsely described items spanning the fifteenth to the end of the eighteenth century. While they were catalogued, they were not classified and were arranged on the shelf merely by date and then by size.

As with many institutions' special collections, description of this material had taken a lower priority due to low use and lack of expertise in identifying the material. There were several events that precipitated retrospective work with the rare collections:

- More than a quarter of a storage area on the level below the library had uncatalogued materials that were rare, fragile, or otherwise difficult to deal with material and needed specialised description.

- The discovery system in use at the time could only map either 260 or 264 fields, so use of RDA became mandatory moving forward, as records for newly published material are generally using the 264 field as part of the RDA standard, but we were left with an issue regarding rare materials. As OCLC's "Bibliographic Formats and Standards" page notes: "these guidelines do not address the application of the 264 field for materials cataloged under the standards for Descriptive Cataloging of Rare Materials (DCRM) or other standards for specialized materials. The communities working on the application of RDA for specialized materials will need to develop appropriate guidelines for using the 264 field with those materials.”

- Mannix Library was participating in a group catalogue project with OCLC that required catalogue records to be uploaded and matched on the Australian National Bibliographic Database (usually referred to as Libraries Australia and the public interface known as Trove-trove.nla.gov.au). During the course of this project, the National Library identified provenance information that they were keen to harvest from the records, however, they required the use of properly constructed 561 fields.

- A research project (Australian Research Council Discovery Project-purl.org/au-research/grants/arc/DP170100426) was looking at possible important provenance and required a retrospective examination of materials published to 1886. Any discovery of the provenance and identifying markings needed to be added to the catalogue record. Additionally, as the project involved an examination of this material from an art collector's point of view, relator terms regarding to illustrators needed to be added to records where they did not already exist.

Because the project largely involved many uncatalogued materials, it was decided that the DCRM(B) convention be used for all rare materials as it is compatible with RDA and because much of the material would result in a unique, richly described record that was beneficial to the National Library and, by extension, the group catalogue project that was being committed to. Shortly after this group catalogue was completed, the decision was made to move to OCLC's WorldShare Management Services as a platform. This enabled direct enhancement of the OCLC master records for these rare materials.

Huw Sandaver is Technical Services Librarian at the Mannix Library. 


\section{WORKFLOW}

First, existing records had to be altered to conform with RDA conventions and the requirements of the National Library of Australia using MARCedit. This involved transforming by bulk fields that are part of RDA that are known to exist for each of the records.

\section{MARCEDIT TRANSFORMATIONS}

\begin{tabular}{|c|c|}
\hline Field & Transformation \\
\hline 040 & \$erda\$edcrmb \\
\hline 100 & \$eauthor.\$4aut \\
\hline 260 & $\begin{array}{l}\text { Convert to } 264 / 3 \text { or } / 4 \text { where appropriate, retrospectively } \\
\text { work to apply correct transcription of place names }\end{array}$ \\
\hline 336 & text $\$$ btxt $\$ 2$ rdacontent \\
\hline 337 & unmediated $\mathbf{\$ b} \mathbf{\mathbf { S }} \mathbf{2}$ rdamedia \\
\hline 338 & volume\$bnc $\$ 2$ rdacarrier \\
\hline 500 (where field contained “Ex libris:”) & $\begin{array}{l}\text { Convert to provenance note field as out outlined by } \\
\text { DCRM(B) (561 } \| \text { a[String] } \$ 5 \text { Code) }\end{array}$ \\
\hline
\end{tabular}

After the mass edits were made to the Mannix records, they were prepared for matching with the Libraries Australia records, after which the provenance information included with the Mannix records was available on the national level (image 1).

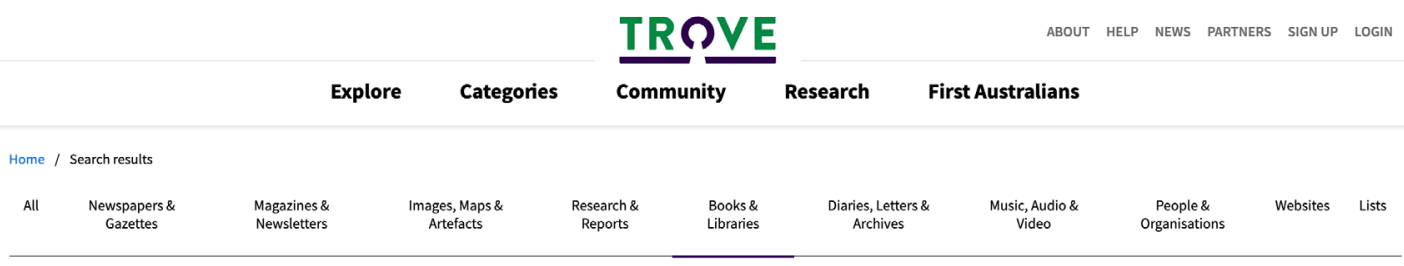

\section{Books \& Libraries}

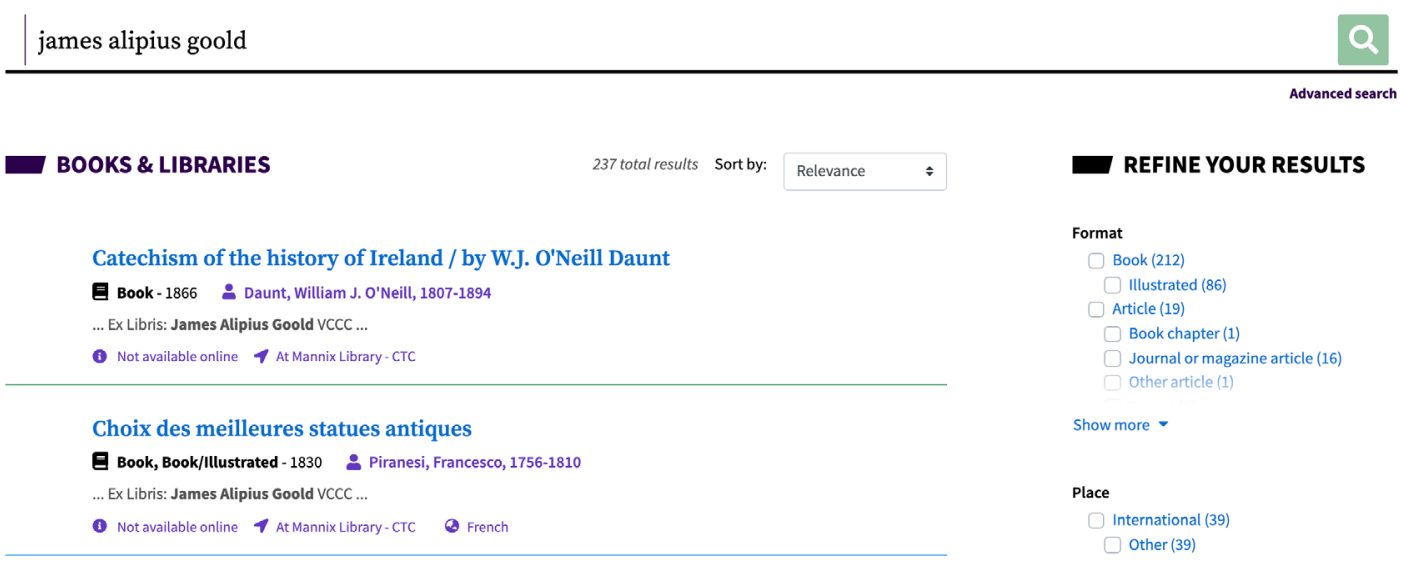

Image 1: Trove screenshot showing provenance and location "At Mannix Library." 
Subsequent to the Libraries Australia project, the decision was made to shift to OCLC's WorldShare Management Services. Because of the previous Libraries Australia data migration project, the data was already well prepared to match with the WorldCat master records. The data migration process allowed our DCRM(B) records to be integrated with the WorldCat master records allowing our provenance and specialised research around specific items to be displayed in a more global context than had previously been available just through Trove (image 2).

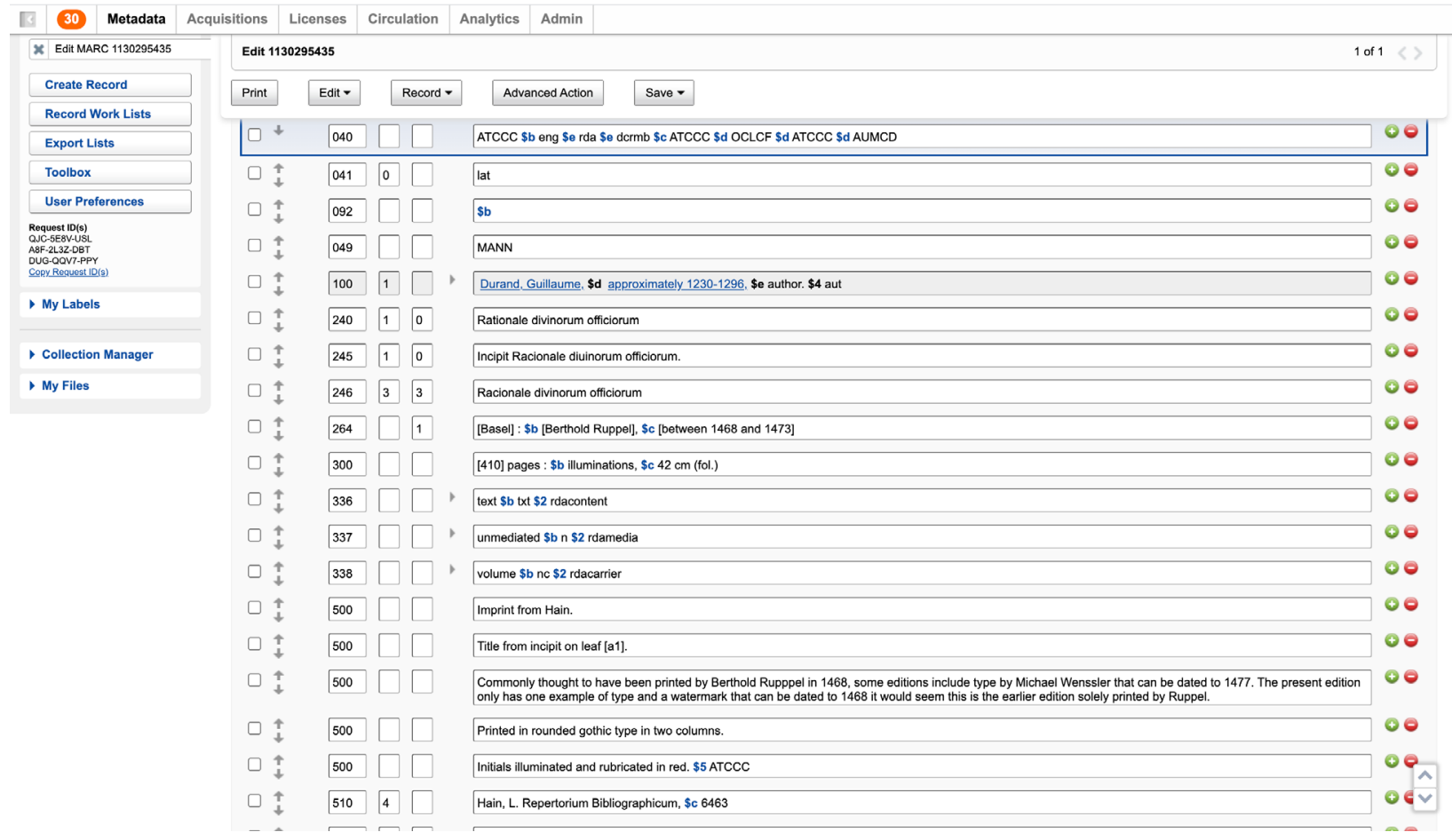

Image 2: WorldCat Master Record for OCLC No 1130295435 showing full DCRM(B) description.

WorldShare's cataloguing tools allow for many "field strings" to be pre-constructed. This allowed for us to construct the entire RBMS Controlled Vocabularies as a custom authority file, greatly speeding up the process for creating an extremely detailed record. In the records for items identified as rare, our policy is to record binding information, paper types, watermarks, printing formats, provenance evidence and type evidence where they are verifiable (image 3 ).

Additionally, because much of the material that was examined as part of the Australian Research Council Discovery Project involved an explicit identification of illustrators, after identification within the works themselves, the OCLC master records were enhanced with a more granular application of relator terms. For example, where artists were known to work in a specific medium. Where individual prints listed both illustrators and engravers this distinction is made in the record (image 4).

Retrospective cataloguing work continues with the Mannix Library collections. After five years of this work, the Rare and Special Collections have expanded from roughly two thousand items to over ten thousand items. All rare or special items now have a holding attached to at least a full-level 
RDA OCLC master record. These records continue to be enhanced where our research identifies information or description not present already in the record.

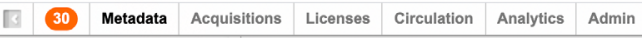

\begin{tabular}{|c|c|c|c|}
\hline \multicolumn{3}{|l|}{ Edit 1130295435} & \multirow[t]{2}{*}{1 of 1\langle\rangle} \\
\hline Print & Edit - Record - & Advanced Action & \\
\hline$\square \uparrow$ & $655 \square 7$ & Calf bindings (Binding) \$2 rbbin $\$ 5$ ATCCC & $\oplus \bullet$ \\
\hline$\square \uparrow$ & $655 \square 7$ & Wooden boards (Binding) \$2 rbbin \$5 ATCCC & $\odot \odot$ \\
\hline$\square \stackrel{\uparrow}{+}$ & $655 \square 7$ & Handmade papers (Paper) \$2 rbpap & $\odot 0$ \\
\hline$\square \pm$ & $655 \square 7$ & Antique laid papers (Paper) \$2 rbpap & 00 \\
\hline$\square+$ & $655 \square 7$ & Chainlines (Paper) \$2 rbpap & 00 \\
\hline$\square \nsubseteq$ & $655 \square 7$ & Wire lines (Paper) \$2 ropap & $\odot \odot$ \\
\hline$\square \ddagger$ & $655 \square 7$ & Watermarks (Paper) \$2 rbpap & $\odot$ \\
\hline$\square \stackrel{+}{+}$ & $655 \square 7$ & Follo format (Printing) \$2 rbpri & 00 \\
\hline$\square \nsubseteq$ & $655 \square 7$ & Bookplates (Provenance) $\$ 2$ rbprov $\$ 5$ ATCCC & $\odot \odot$ \\
\hline$\square \pm$ & $655 \square 7$ & Marginalia (Provenance) \$2 rbprov \$5 ATCCC & $\odot \odot$ \\
\hline$\square \pm$ & $655 \square 7$ & Black letter types (Type evidence) \$2 rbtyp & $\oplus$ \\
\hline$\square \ddagger$ & 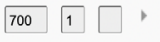 & Ruppel, Berthold, \$d -1494 or 1495 , \$e printer. \$4 prt & $\oplus \bullet$ \\
\hline$\square \ddagger$ & $700 \quad 1 \square$ & Gallician, Anton, \$d 1429-1497, \$e papermaker. \$4 ppm & $\odot \bullet$ \\
\hline$\square \stackrel{+}{+}$ & $700 \square \square$ & Sticht, Robert Carl, \$d 1856-1922, \$e former owner \$4 fmo & $\odot 0$ \\
\hline$\square^{+}$ & $752 \square \square$ & Switzerland Sd Basel & $\odot$ \\
\hline \multicolumn{4}{|l|}{, LBD (0) } \\
\hline \multicolumn{4}{|l|}{ - LHRs (1) } \\
\hline Move LHRs - $]$ & View/Edit in Text View & & \\
\hline
\end{tabular}

Image 3: Genre tags in OCLC Control No 1130295435, auto inserted via Record Manager's "Field Strings" function.

UNIVERSITY OF DIVINITY pictorial edition of the works of Shakespere
Q Advanced Search

(D) Searching may be impacted during service changes - please contact your local library for help

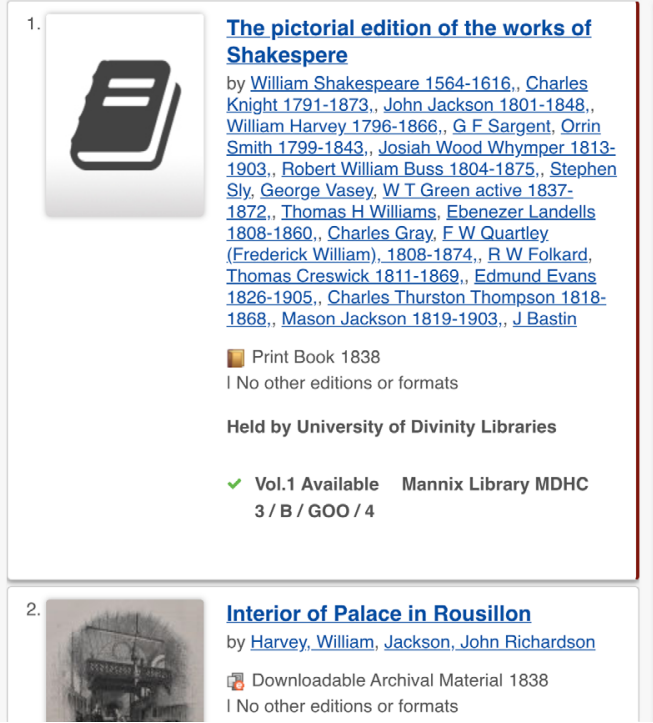

The pictorial edition of the works of Shakespere

$\boldsymbol{x}$

G6 Cite \& Link Email is Save

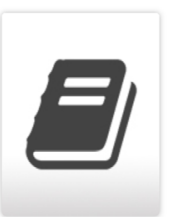
by William Shakespeare 1564-1616, (Author), Charles Knight 1791-1873, (Editor), John Jackson 1801-1848, (Engraver), William Harvey 1796-1866, (Illustrator), G F Sargen (ilustrator), Orrin Smith 1799-1843, (Engraver), Josiah Wood Whymper 1813-1903, Wor engraver), George Vasey. Wood engraver), W T Green active 1837-1872, (Wood engraver), Charles Gray. (Engraver), F W Quartley_(Frederick William), 1808-1874, (Illustrator), R W Folkard (lllustrator), Thomas Creswick 1811-1869, (lllustrator), Edmund Evans 1826-1905 (Encrer), Charles Thurston Thompson 1818-1868, (Wood Edmund Mason Jackson 1819-1903, (Engraver), J Bastin (Engraver)

D. Print Book 1838

Held by University of Divinity Libraries

(1) View Description

(1) Browse the Shelf

\section{- Check Availability}

- University of Divinity Libraries

3 available Place Hold

Image 4: WorldCat Discovery displaying relator terms in OCLC No 1017276602. 


\section{FUTURE WORK}

Cataloguing work continues with the special collections with a digitisation project for rare prints also being harvested to various platforms, including the Atla Digital Library, OCLC WorldCat through the Digital Collection Gateway, and JSTOR Community Collections. Additionally, linked data is also being used with IIIF manifests to allow for virtual exhibitions of works contained in the collection, and linked data is also used heavily in JSTOR Forum (image 5). There are two metadata standards in use with these platforms. Our Omeka and CONTENTdm repositories both use Dublin Core Metadata, and JSTOR Forum uses VRA Core to describe the materials. When creating the IIIF manifest, the metadata standard is also VRA Core. All of our digital collections use Getty Vocabularies consistently over Library of Congress, as these are specifically created for use with visual works.

All of our digital collections now use linked data. Our Omeka collections output both RDF and JSON formats. Our CONTENTdm collections are harvested into JSTOR Forum, which uses linked data heavily with the Getty Vocabularies (the Union List of Artists Names, the Art and Architecture Thesaurus, and the Thesaurus of Geographic Names).

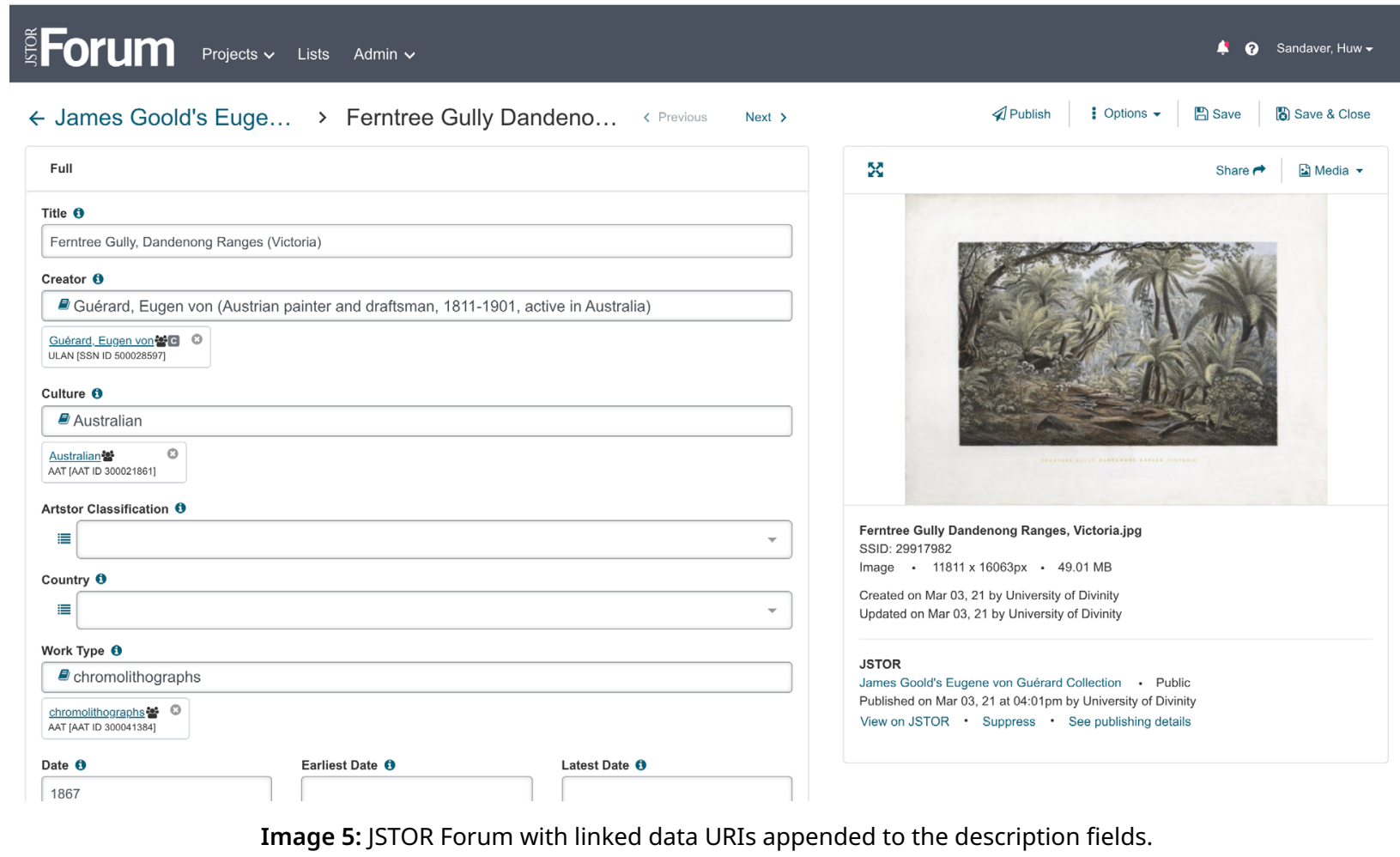

Our IIIF manifests are created using JSON-Linked Data format, allowing us to take the same metadata represented elsewhere and display it in any service that can display or proxy the manifest, including Mirador and Universal Viewer (image 6).

Over the last six years, Mannix Library's Rare and Special Collections have completely transformed. From two thousand sparse MARC records to now over ten thousand richly described MARC, Dublin/VRA Core Records with visual works represented using Linked Data, our collections are now future proofed and ready for discovery. 


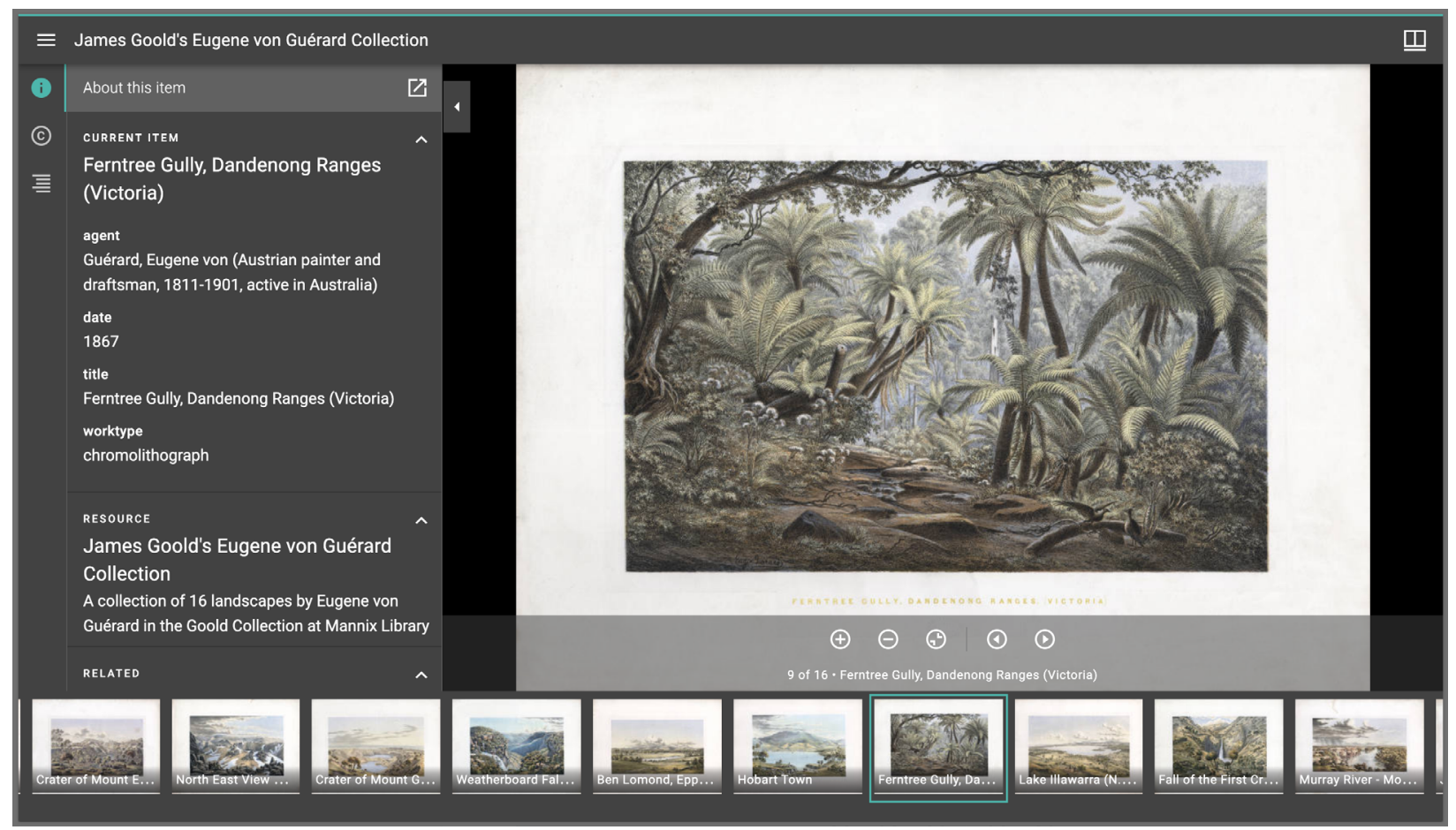

Image 6: IIIF Manifest using VRA Core metadata (underlying code is JSON-Linked Data). 